\title{
Harmonious Society and Change of the Concept of Local Legislation
}

\author{
Jingbo Zhao \\ School of Law, Changchun University of Science and Technology \\ Changchun 130022, Jilin, China \\ E-mail: zhaojingbo@gmail.com
}

Received: January 4, 2011 Accepted: January 18, $2011 \quad$ doi:10.5539/ass.v7n5p197

\begin{abstract}
Local legislation is an important component of the national legislation system. In face of conflicts and contradictions between subjects of the multiple interests in the modern society, it seems extremely critical how to play the role of local legislation in establishment of a harmonious society. Development of practice needs change of the concept. The principle is the guide of legislation, while a scientific principle is the foundation and precondition of harmony of local legislation. In establishment of the harmonious socialist society, we have to update the principle of development of local legislation. The concept of local legislation is changed with appropriate expansion of local legislation authority, transition of local legislation from emphasis on subordination to emphasis on autonomy and transition of local legislation from emphasis on economical legislation to emphasis on diversified legislation.
\end{abstract}

Keywords: Harmonious society, Legislation concept, Legislative authority, Autonomy

The essence of the issue of "establishing" a harmonious society is not to establish a society that has no interest contradiction and conflict at all, but to set up a society which is able to coordinate, integrate or control interest contradiction and conflict on the basis of contradiction and conflict of interest. (Li Lulu, 2005) In face of conflicts and contradictions between subjects of the multiple interests in the modern society, it seems extremely critical how to play the role of local legislation in establishment of a harmonious society. In the following, we are going to analyze the importance of local legislation in establishment of a harmonious society and demonstrate change of the concept of local legislation in the harmonious society from the three perspectives of appropriate expansion of local legislation authority, transition of local legislation from emphasis on subordination to emphasis on autonomy and transition of local legislation from emphasis on economical legislation to emphasis on diversified legislation.

1. In the process of development of the national government by law, the effect of legislation in the society has been more and more prominent, and has become a kind of power which is separated from local administrative authority and judicial authority. Although local legislation in China occupies a relatively low level of position compared with the central local legislation, it has played a significant role in legal construction and in the whole social life. During historical transition of local legislation, special research on local legislation has not been paid due attention compared with researches on other fields. Insufficiency in the theory will necessarily lead to blindness of practice. Legislative lagging, legislative conflict and legislation exceeding authority in local legislative practice emerge as inharmonious notes in the entire legislative movement. In Reports on the $16^{\text {th }}$ National Congress of Communist Party of China, the General Secretary Hu Jintao definitely pointed out, the harmonious socialist society to be built ought to be a society with democratic government by law, justice and fairness, honesty and fraternal love, full of life, stability and order and harmonious contact between human kind and the nature. Local legislation is both a legal fact and a kind of value orientation about social development, which has continuity and stability. Coordination and harmony of local legislation and central legislation as well as the subjects of local legislation and overall development of local legislation are all related with the progress of the national government by law and fulfillment of a harmonious society.

According to ideologists in ancient China, the law was "the formula of the society" and "the instrument of all" in terms of its function. As a kind of social standard, legislation should not only be complete and definite, but also should be coordinated and unified. Only if coordination between the central government and local government and between different local governments is realized, can it be likely to offer a definite direction and clear-cut behavioral normal form for human being. If legislation is lacking in coordination and consistency as one of the 
standard behavioral norms for human being, then it will lose its significance of existence. Just as some scholars pointed out, “...Conflicting law might bring about contradictory information and conflicting value to the society, as a result of which the ideal of government by law can only result in social confusion... The reason why knowledge of law and professions associated with law can become the independent power to build up and adjust social relationship, to a large extent, is that the knowledge of law itself constitutes a consistent system. This consistency is able to generate a tense relationship between common social life, and builds up government by law and constitutionalism that is established and thus becomes the indispensable regulator of the society." (He Weifang, 1998)

Legislation is the most concentrative expression and manifestation means of people's will and interests, the institutional distribution of social resources, rights and interests, etc, and is the foundation for enforcement of the law. Thus, in the modern society which rules by law, whether legislation reflects and balances all sorts of different interests is directly related with success of constructing a harmonious society (Lu Guolia, 2006). In this sense, it seems extremely important to strengthen legislative task and improve legislative quality in constructing a harmonious socialist society. A scientific and rational legislation is able to realize optimal allocation of resources, realize the maximization of interests and balance the value of fairness, efficiency and order, etc. As a component of the national legislation, local legislation has undergone the routes of exploring starting, accelerating development and scientific standardization in the past more than 20 years and has played an irreplaceable role in propelling and securing the successful ongoing of the reform and opening up. Under the great background of constructing a harmonious socialist society, it is a brand-new subject we are faced up how local legislation should keep pace with the times, adapt to the new requirement of constructing a harmonious socialist society, make contributions for construction of a harmonious society out of consciousness and realize a benign interaction with the overall development of local economic society. Local legislation is an important component of the national legislative system, and will necessarily play an enormous role in constructing a harmonious socialist society.

Firstly, local legislation has the function of legal guarantee. Modern society is a society with differentiated interests, which determines that it has to have a power to propel, maintain and secure harmony that can predominant and control the antagonistic relations of interests. This power is law, and can only be law. Local legislation has the following functions in legal guarantee. Firstly, local legislation guarantees the effective implementation of constitution, law and administrative rules and regulations in local area. Legal rule itself is abstract and recapitulative. Besides, China is a big country with vast area of land, large population and imbalanced development of politics, economy and culture in different areas. Legal and administrative rules and regulations set up on that basis unavoidably have the characteristics of principle and abstractness. However, local legislation can formulate local rules or governmental regulations according to the principle and spirit of the national laws and administrative regulations by taking into consideration the actual condition of local area, so as to materialize the constitution, law and administrative rules and make up for disadvantages of higher-level law. Secondly, local legislation has the function of "test field". Currently, China is at a stage of social transition and reform development. Thus, during this particular period, as for some new subjects, the central legislation has not yet been formulated and still leaves for "blankness". Those local areas which allow economy to be developed first are one step ahead in terms of legislation, which may accumulate experiences for unified legislation of the nation. Thirdly, local legislation is able to give play to the independence of local areas with different actual situations. Some matters are purely local or with local features, which, generally speaking, don't need always or within a foreseeable period of time to be stipulated by the nation by formulating laws and administrative rules and regulations.

Secondly, local legislation has the function of convergence and communication. The essence of socialist legislation is to guarantee and fulfill the democracy of the people, fully express and effectively converge people's appeal of interest and proposition of will in the frame of democracy and government by law, and escalate into the will of the nation through legislative procedures. The more fully expressed and the more completely converged the will of the extensive public through legal system and procedures, the more legislation is able to incarnate the democratic value of people ruling by themselves. Then, the public are willing to express their will and pursue their interests by legal means. As a result of the diversification of interests in the modern society, differentiation of the demands of the public and the diversity of people's cognition, local legislation has to face up with complicated issues or contradictions and confront the legislative appeal of the public to acknowledgement and protection of legislative institutions in terms of various opinions and different interests. This not only calls for communication of legislative institutions with the interested party involved in the legislation so as to know about the demands of the public and interpret concerns of legislative institutions, but 
also requires communication between all the interested parties involved in the legislation, with the purpose of fully stating their own viewpoints and reasons and confirm their stand in and demands on the legislation. On the basis of fully advocating democracy and mutual communication, we should seek for a project for all parties to reach a consensus.

Finally, local legislation has the function of direction and propaganda. In the process of constructing a harmonious socialist society, local legislation not only has to adapt to requirements of social development and transition, but also has to advocate the value concept of mainstream consciousness ideology in an active attitude. Local legislation should, out of consciousness, lead the public with a rational longing for the legislation, influence the public and the society with knowledge and belief in law and enable legislative process to become the process of advocating the value concept of a harmonious society, such as, democratic government by law, fairness and justice, integrity and fraternal love and stability as well as order, become the process which enables the public to learn knowledge of law, understand spirit of law, accept concept of law and recognize the criteria of law, and become the process in which all subjects of legal relations define their specific rights and obligations, authority and responsibility and accept the legal constraint out of consciousness. (Xie Zeguang, 2006)

2. Development of practice calls for change of the concept. The primary issue of the existence of local legislation is insufficient cognition in the interests behind legislation or improper adjustment of interests. Legislation is not only a process in which the social relations are realized and confirmed, but is also a process in which interests are distributed. In the process of development of human society, human beings have never ceased longing for demands and pursuing of interests, which is the result of the natural instinct of human kind. In this process, how to take an overall consideration of the interests of the nation, the collective and individuals and realize a coordinated development of their interests is a consistent position of the Communist Party of China and is also the central issue that is urgently required to be resolved in the practice of legislation. As local legislation, whether it can correctly know and grasp the mainstream social relationship in a particular period and whether it can correctly embody the value concept of socialism is the entire standard of legality of its content origins. Thus, correct knowledge in all sorts of social interests in the premise to make perfect work of local legislation.

As a conscious activity of human being, legislation is a kind of activity in which subjectivity is reflected in objectivity. Only when interest is realized by lawmakers and considered important and necessary to be adjusted with legal methods, can interest be fixed in legal standards. However, interest that has not yet been realized or considered not important should not be stipulated in legal documents. In order for local legislation to start out from reality, "a lawmaker has to regard himself as a natural scientist. He is neither making the law nor inventing the law, but merely stating the law and expresses the internal rules of spiritual relationship in existing law with consciousness." (Karl Marx and Frederick Engels) According to Marx, any legislation in a civilized society is nothing more than a process in which the ruling class escalates their own interest demands and all interest relations required to maintain the social order to the will of the nation through definite approaches and means. Therefore, interest has the effect of uncontroverted restraint on legislation. Interest is independent of the legislation to exist, which is determined by the effect of all sorts of rules in the society on the subject and by the social environment in which the subject is in. Since the society is developing and changing, all sorts of interests in the society are also always changing. Hence, any law made has to be continuously amended or abolished with transition of the society. Local legislation ought to establish correct interest concepts and cope well relations between the interest of the country and interest of local area, long-term interest and short-term interest, local interest and department interest and interest of a country and the entire interest of the world. If local legislation doesn't know clearly about interest, misplaced distribution of interests might be caused. The mistake of local protectionism legislation and department protectionism legislation is that they have not had a clear idea about interest and have not been able to correctly coordinate and accept or reject interest. (Zhou Wangsheng, 2001)

Idea is the guide of legislation and scientific idea is the foundation and premise of harmony of local legislation. In the process of establishing a harmonious socialist society, development of local legislation has to upgrade the idea, and first of all, establish the right-based idea. People are the origin of all national rights and execution of the public rights of the country is for the rights, interests and happiness of the public. We have to fully guarantee that people have the opportunity to participate on the basis of democracy and guarantee the openness and transparency of execution of the public rights of the country. Influenced by the tradition obligation-based concept in China, the starting point of former local legislation was usually how to fulfill the national authority and how to realize administration, but not to provide better service. This idea is incompatible with harmony of the society. In a harmonious society, the relationship between the government and the people should be a mutual trust relationship of service and cooperation, but no more the confrontation relationship of order and obedience in the traditional sense. That is, to emphasize that the purpose of the government executing its authority is not 
merely for "administration", but that the government is able to better and more effectively offer better service for the whole people and the entire society. Secondly, we should set up the idea of government responsibility. Responsibility always follows after rights. Thus, rights without fetter of responsibility will lose the bound of executing the rights, as a result of which usually abuse of the rights by authority owners. The function of responsibility is not only to punish, but also to prevent, which can indicate the negative evaluation of the country and the society on those authority owners who violate the law or abuse the rights so as to restrain the impulse of authority owners from abusing the rights.

3. In the following, the author is going to expound changes of the concept of local legislation under the perspective of the harmonious society in the three aspects of separation of powers, consciousness of innovation and focus of legislation.

\subsection{The concept of separation of powers: appropriate expansion of local legislation powers on the premise of unification of legal system}

Since the reform and opening up, under propelling of the economic system reform, relationship between the central government and local governments has taken great changes, which has gradually the relation mode of central government and local government under the centralization system. Since 1978, mainstream of the reform in the relation between the central government and local governments was devolution and assignment of powers and former one-class legislative system was reformed and two-class legislative system was definitely established. Local Organization Law that was formulated in July 1979 entrusted the authority to provincial People's Congress and its Standing Committee to formulate local rules and regulations. In December 1982, Local Organization Law made corresponding amendments. That is, the People's Congress and its Standing Committee in cities as provincial capitals and those large cities approved by the State Council were also had the authority to formulate drafts of local rules and regulations according to the specific situation and actual needs. In December 1986, the Local Organization Law was once again amended, in which under the precondition that the People's Congress and its Standing Committee in cities as provincial capitals and those large cities approved by the State Council did not come into conflict with the constitution, law, administrative rules and regulations and local rules and regulations, they had the authority to establish local rules and regulations. In 1984 and 1988, the State Council successively approved 18 "large cities" three times according to the population size of the cities, the comprehensive economic strength of the cities and the modernization progress, and entrusted the authority of formulating local rules and regulations. In 1992, in his talk in South China, Deng Xiaoping proposed the target of reform to establish socialist market economic system. The Fourteenth CPC National Congress put forward clearly the viewpoint of establishing the socialist market economic system, which laid an economic foundation for irrational establishment of the relationship between the central government and local governments. The constitutional amendment in 1993 put into the nation's highest law the contents of "implementation of socialist market economy" and "strengthening economic legislation and improving macro-control", etc. In 1994 and 1996, the four cities of Shenzhen, Xiamen, Shantou and Zhuhai were endowed with the authority to formulate rules and local regulations, which indicated further expansion and enlargement of the local legislative authority in China.

From the historical development of the legislative authority relation between the central government and local governments, separation of power has always accompanied with development of the legislative relation between the central government and local governments and high and complete concentration of power has never occurred. "Complete concentration of power and separation of power is just the two ends of the ideal, and a legal community has to have minimum concentration of power and maximum separation. Otherwise, the legal community might go towards collapse. (Kelsen, 2003) From formulation of local legislation to concentration and devolution of powers of the relation between the central and local legislation, especially devolution of power after the reform and opening up, there has had a motive behind. Marketization of economy urgently requires response of local legislation. Practice of the relation of central and local legislation indicates, separation of local power and devolution of power have not led to danger of "local separation". On the contrary, local legislation has had the good effect of demonstration and has offered rich legislative experiences for central legislation. This is just the so-called "If the head of a country is trivial, then his ministers will indolent and all will be indolent!" Kong Anguo in Han Dynasty interpreted, "If the head of a country is trivial and embraces with no ambition in his mind, then all his ministers will get lazy and everything will be neglected." (Huo, Cunfu, 2003) Hence, enthusiasm of the central government and local governments is quite critical in devolution of power. The problem of local separation of power also does not lie in the issue of devolution and retaking of power, but how to devolute the power in a correct way. Expansion of local legislative power doesn't mean that the more the power, the better it is, or the larger the power, the better it is, but means that we should give full play to 
autonomy of local legislative power and regard execution of power as the standard to adapt to the social development and add to social welfare.

\subsection{Innovation consciousness: transfer of local legislation from focus on subordination to focus on autonomy}

As far as the relation between national legislative power and local legislative power is concerned, countries with the unitary system and countries with the federal system have different understandings in the relation between the central government and local governments and in the property of local legislative power. In countries with the unitary system, the relation between the national legislative power and local legislative power is subordinate. "Local legislative power has to be subordinate to the central legislative power, local legislation has to report to the national legislative organ for the record or approval and implementation of local legislative power shouldn't come into conflict with the national legislative power. Otherwise, the national legislative organ is entitled to repeal the local legislation or the local legislation will be invalid automatically." (Zhou Wangshen, 1998) The relation between the national legislative power and the local legislative power in countries with the federal system is semi-independent and semi-subordinate. The national legislative power and local legislative power are not only independent, but also restrain each other, mostly the national legislative power restraining the local legislative power. Both the national legislative power and local legislative power execute their legislative power within their own particular legislative jurisdiction scope. Both the national legislation and local legislation have to try to comply with the national and local interests and enable interests of both sides guaranteed. However, as long as the nation and local area are concerned, the nation is put in the first place. And the national legislative power is constrained by local legislative power on specific matters and in specific procedures." (Liu Jingwei \& Huang Xun, 2004) As for countries of central authority with the unitary system, the relation between existing national legislative power and local legislative power is mainly subordinate.

Local legislation has the double attributes of subordination and autonomy. Local legislation in China has to follow the principle of unification of central legal system and shouldn't come into conflict with laws and administrative laws and rules. Following the principle of lower-level law not violating higher-level law, the local legislation has to carry out and reflect the spirit of central legislation. Meanwhile, the constitution stipulates that, local governments "formulate local laws and rules according to specific situation and actual needs", which endows local legislation the independent autonomous right. Ever since a long time, affected by traditional concepts, local legislation has always been focusing on central legislation and most content of local legislation is repetition and reproduction of central legislation, lacking in autonomy and initiative, and local legislation is not enough in the consciousness of innovation. Autonomous legislation has the effect of pilot and innovation. In such a big power as in our country, it is unlikely that there is no concentration and legal system unification and concentration of legislation and there is no particular local interest. If all local legislations are nothing but simple repetition of central legislation, then there is no need and significance to entrust the local legislative rights. Only if the principle stipulation of the central government and the actual situation of local areas are taken into an overall consideration, can local legislation be pioneering, innovative and effective. Furthermore, peculiarity of coastal cities, economically special zones, special administrative regions, national autonomous areas and special zone with "one nation, two system" has determined that the unitary legislative system in our country no longer adapts to the changes of the times and appropriate devolution of power in legislation is urgently required. Taking legislation in those provinces and cities in western areas with economic backwardness as an example, for quite a long time, resource-based enterprises are their backbone of economic development and their processing industry and high-tech industries are backward, so their conditions of attracting investment are also inferior to eastern provinces and cities and their finance is usually difficult. Under such a circumstance, if "devolution of power" is not executed in terms of development and utilization of local resources, then a vicious circle will be necessarily caused in a large gap in economic development between those western areas and other areas, and more serious social instability issues might be caused thereof. Therefore, positive guidance of independent legislation to exploit to the favorable conditions and avoid unfavorable conditions is the objective and necessary requirement for economic development of these provinces and areas.

Construction of a harmonious society has to be based on overall and in-depth implementation of the basic strategy of governing the country by law and creation of a good legal environment. Legislation is a critical aspect of establishment of legal system. A harmonious society is one with harmony of human and human, human and the nature and human and the society. In the economic society, we indeed need a lot of economic laws and rules to maintain the market order and protect the rights of stakeholders. At the time when economic legislation occupies a predominant position, other laws and rules have to give place. "Under such a legislative thought, the unicity of human being is highlighted in that human being has not only become an economic man in terms of economy, but has become an economic man in all aspects of the social life, especially in terms of law in which 
human being has become a 'dimensional man' with the scale of economy". "Under this thought, the actual feature and diversity of legislation has disappeared and has evolved into the shadow of economic development, imitating at every step, and such a sort of legislation can also be termed as "dimensional legislation" in a certain sense. (Zhou Wangsheng, 2003) Nevertheless, what we need currently is not merely economic and legal criteria, but more importantly, we need legislations in terms of social security, environmental resources protection, humanistic and scientific education and guarantee of citizens' democratic rights, which are supposed to fulfill organic unification of interests between economic man and moral man. Faced up with conflicts of interest between multiple stakeholders and with games in choice of value, it is without doubt that criteria in social security, environmental resources protection, humanistic and scientific education and guarantee of citizens' democratic rights have made up for weakness of economic legislation in pursuit of profits and have become the legislative supplementation to regulate and balance interests. So far as relation between human kind and the nature is concerned, at the time when human kind utilizes the nature and remakes the nature, they are also or will damage the nature and destroy the environment in which human kind relies on. Construction of a harmonious relation between human kind and the nature in a harmonious society calls for concentration of human kind on protection of the environment, protection of the sustainable natural environment and realization of intrageneration equity and intergeneration equity. In terms of the relation between human kind and the nature, the "inharmonious" phenomenon existing in the society is the presentation of contradiction between economic foundation and superstructure. And establishment of a harmonious society has to continuously regulate contradictions and conflicts and carry out laws and rules in terms of social management, economic construction, social security, social development and spiritual and civilization construction, etc.

\section{References}

Guan Zi---Ming Fa Jie.

He, Weifang. (1998). The Idea and System of judicature. China University of Political Science and Law Press, p296.

Huo, Cunfu. (2003). Field of Authority. Shenyang Publishing House, p15.

Karl Marx and Frederick Engels, Vol. 1. (1972). People's Publishing House, p296.

Kelsen. (2003). General Theory of Law and State. Encyclopedia of China Publishing House, p338.

Li, Lulu. (2005). Harmonious Society: Coordination and Combination of Interest Contradiction and confliction. Exploration and Free Views, 5.

Liu, Jingwei \& Huang, Xun. (2004). Thought on the Issue of Innovation in Local Legislation. Democracy and Legal System, 3.

Lu, Guolian. (2006). Democratic Legislation and Social Harmony, May 15. [Online] Available: http://www.chinapublaw.com/.

Xie, Zeguang. (2006). Important Role of Local Legislation in Construction of a Harmonious Socialist Society, June 12. [Online] Available: http://npc.people.com.cn/GB/14957/index.html.

Zhou, Wangsheng. (1998). Legislative Science. Law Press, p248.

Zhou, Wangsheng. (2001). Study on Legislation. Law Press, Vol. 3, p497.

Zhou, Wangsheng. (2003). Study on Legislation. Law Press, Vol. 4, p9, p463. 